\title{
How to Cultivate the Innovative Thinking Way of Students in the Teaching of Animation Key-frame Design
}

\author{
Shaohui LIU \\ Art Academy \\ Northeast Agricultural University \\ Harbin, Heilongjiang Province, China
}

\begin{abstract}
Animation Key-frame Design (i.e. animation action design) is a process of key-frame designer to complete one of the roles according to the development of animation and the intention of director. Animation Key-frame Design is a comprehensive teaching process with both practical and innovative characteristics. To learn this course, a higher requirement is proposed on the practical ability and innovation ability of students. In order to cultivate the keyframe designers meeting the development of the modern society, it is necessary to let the students master relevant design skills and also lay an emphasis on the cultivation of students' innovative thinking, innovation ability, and ability to imagine in the process of training students. In this paper, the methods for cultivating the innovative thinking in the teaching of Animation Key-frame Design are mainly analyzed.
\end{abstract}

Keywords- the teaching of animation key-frame design; students; innovative thinking

\section{INTRODUCTION}

Animation Key-frame Design (i.e. animation action design) is a process of key-frame designer to complete one of the roles according to the development of animation and the intention of director. The design includes facial expression, action, etc. In the process of animation design, key-frame creation personnel should undertake the specific designs and creations. However, Animation Key-frame Design shoulders the important task of the key-frame creation personnel. In this phase of the design, the keyframe creation personnel need to give a comprehensive consideration to the requirements of animation companies and the specific circumstances of the works, so as to carry out the design work. Considering this factor, learning can't be completely implemented according to the phase courses in the teaching of Animation Key-frame Design and students should be helped according to the relevant teaching methods so as to let them know well the relevant skills within the limited time. In this way, a solid foundation can be laid for the follow-up study of the students.

\section{NECESSITIES OF CULTIVATING ST UDENT S INNOVATIVE THINKING IN THE TEACHING OF ANIMATION KEY-FRAME DESIGN}

In order to cultivate the key-frame designers meeting the development of the modern society, it is necessary to let the students master relevant design skills and also lay an emphasis on the cultivation of students' innovative thinking, innovation ability, and ability to imagine in the process of training students. Thus, the ability of students to innovate is gradually improved. In the concrete teaching process, it is necessary to help students quickly grasp the characters and task models of the animation roles and understand the specific requirements, and then they can put into design by playing their own creativity and imagination. Based on this factor, it is necessary for the animation teachers to break the traditional teaching model with great efforts and carry out the innovative practice in the teaching of Animation Key-frame Design, for the purpose of cultivating all-around innovative creation personnel.

\section{THE APPROACHES TO ANIMATION KEY-FRAME} DESIGN TO CULTIVATE ST UDENTS' INNOVATIVE THINKING

\section{A. Change the Traditional Teaching Way}

Essentially, animation art is to describe a state of life by relying on high-tech methods. Under this state, culture is an important reflection. From a macro-perspective, it is necessary to actively apply Chinese culture to the teaching activities, selectively absorb cultural essence, and let students create animation works with special characteristics, for the purpose of realizing the development of Chinese animation works. This can be started from the following several aspects.

First, students should be encouraged to think.

The core of the creative thinking lies in the innovative thinking, and students are unable to achieve innovation if they don't even have the ability to independently think. Essentially, innovation ability is unique creative thinking, and the source of the creative thinking is the curiosity of students. This curiosity can drive students to be initiative in analy zing and exploring problems, and thus the works with innovation ability is designed.

Second, students should be promoted to know how to choose.

The modern society is an information age, in which knowledge is diverse and changes very rapidly. Choice is an important quality, and the applications of animation originality, animation materials, and design result are inseparable from choice. For this reason, teachers must teach students to choose and also gradually improve the 
students' aesthetic thinking and logical thinking in the process.

Third, students should be encouraged to carry out practice.

According to the theories of behavioral science, psychology, and creative study, the ability of a person should be improved in a different practice process. Compared with the learning of theoretical knowledge, higher requirements are proposed by practice for students. In order to improve the innovation ability of students, students should be encouraged to carry out practice. In addition, it is necessary to note that practice is one of the most important factors in the process of influencing personnel's innovation capability. In the field of animation education, teaching is just a practice-oriented guiding activity. In the specific teaching process, it is necessary for teachers to encourage students to think about animation design ideas and constantly enhance students' practical ability and innovation ability using different materials, tools, and methods.

\section{B. Positively Using Classroom Training Method}

In the teaching of Animation Key-frame Design, most teaching contents are explanations to the relevant laws such as the law of natural motion, the law of object motion, and the law of animal motion. These laws have some similarities. In order to develop the innovative ability of students, teachers can actively apply the heuristic teaching approach to classroom teaching, help students summarize the experience in knowledge, and also take some time off for letting students actively practice. After the works is completed by students, teachers can encourage students to adopt the mutual review comments. After the comments are completed, a summary should be given by teachers, in which the progress made by students should be appraised and the shortcomings in the design works of students should be euphemistically proposed, so that students can learn from others' strong points to offset their own weakness and make an improvement in the comments. With the method, the enthusiasm of students in active learning can be well motivated, and then students can develop all types of keyframe design.

\section{Applying the Scene Setting Training Method}

The law of motion such as the law of walking and movement described in Animation Key-frame Design, is only a stylized operation. In the design and practice of these laws, they can be placed in the subsequent stages of the course, set up a corresponding scene for students, encourage students to sort out and collect data, play their own imagination with great efforts, and let students refine their corresponding motion law on their own. This situation setting training method has been widely used in the teaching of multiple courses, and also an ideal teaching effect has been made.

\section{Carrying Out the Creative Imitation Training Method}

In the teaching of Animation Key-frame Design, a great number of students have great dependence on teaching materials; when teachers are arranging the assignments about the practice of the law of motion, many students will copy directly the related illustrations with no new ideas at all, but not work hard to analyze and think. These make the increase of the teaching effect restricted and also go against the all-round development of students. In order to solve these problems, teachers can develop an innovative imitation training method according to the individual differences of student and help students to master relevant knowledge. On this basis, innovation and restructuring are conducted and then creative works can be designed.

\section{E. Helping Students Break the Thinking Set Using Diversified Teaching Methods}

In the traditional teaching activities, teachers provide teaching for students mainly using the combination of theory with computer practice. Although this teaching method is in line with the teaching objective and requirement of Animation Key-frame Design, it is very boring and dull and difficult to inspire students' interest in learning and may result in the negative feelings of students. Thus, it is more difficult to play the innovative thinking of students. In this way, an ideal teaching effect is also difficult to obtain for Animation Key-frame Design.

For example, teachers can provide teaching for students using diverse teaching methods when the animation effect of star motion is explained. In the following, three scenes are set up.

Scene 1: 20 stars are directly placed, and students are required to design the animation motion effects of 20 stars

Scene 2: Only one star is available and certain statements are inserted in it for achieving the animation motion effects of 20 stars

Scene 3: The animation motion effects of 20 stars are directly achieved using statement library

The above 3 scenes contain different knowledge points, but also some similarities. In the actual teaching process, teachers can design the different teaching situations like these and apply different teaching methods to them, so that students can seek ways to resolve the problems from multiple directions and multiple angles and are encouraged to take part in practice and make a scientific comparison after works is completed. Thus, students are not only helped to master relevant knowledge better, and also the traditional thinking set of students is effectively broken and a very positive effect is played on the future employment of students. 


\section{F. Applying the Project Teaching Method}

The contents in Animation Key-frame Design are diverse and also very multifarious, including the principle of animation, the theory of animation, the theory of motion, and animation techniques, and so on. At the present stage, the existing teaching system in China requires students to complete all courses in a certain period of time and does not pay attention to the cultivation of students' practical ability. However, animation companies are eager to seek profits, and are unwilling to participate in the process of training students together with school and also won't accept students for internship. The students cultivated in this way are difficult to meet the development of the society. In order to change this situation, project teaching method should be actively adopted to arrange the teaching work in a planned way and let students know well the animation techniques and laws in the process of practice.

In the teaching of Animation Key-frame Design, school can make cooperation with animation companies in the name of school animation studio. Then, students are required to undertake animation design projects in the process of training students' basic theory and basic skills. In the process of course design, skill training is necessary to combine closely with the practice project training, in which students are divided into different groups. Thus, the training is conducted by the method of group collaboration. In this process, teachers need to carry out the guidance work according to the conditions of diffe rent groups. In the design, teachers need to help students combine the project contents with animation software techniques together and then carry out the guidance work according to the actual conditions of each group. In this way, students are not only helped to flexibly use theoretical knowledge, and also students' awareness in competition and cooperation are improved. As a result, students can fully understand the operation flow of animation companies.

\section{CONCLUSION}

To sum up, Animation Key-frame Design is an integrated teaching process oriented at practice and innovation, and it proposes higher requirements for students' practical ability and innovation ability. In the actual teaching process, teachers need to pay attention to the training of students' innovative ability and design thinking skills, provide a flexible model of practice teaching for students, and cultivate the all-round modern talented personnel.

\section{REFERENCES}

[1] Pingjun YANG. How to Cultivate Students' Innovative Thinking in the Teaching of Animation Key-Frame Design [J]. Dat a of Culture and Education, 2012 (12).

[2] Weihua MA. The Teaching Method Exploration and Practice of Course Flash Animation Technology in Higher Vocational Colleges [J]. Management \& Technology of SME, 2012(02).
[3] Liangming JIN. Innovate the Way of Thinking and Broaden the Way of Thinking-Discussion on AutoCAD Software Teaching Methods [J]. Science and Technology Information, 2010(32).

[4] Xiumin YANG. Extend Individuality and Stimulate InnovationDiscussion on How to Cultivate the Creative Thinking Way of Higher Vocational Students [J]. Science and Technology Information, 2008 (13)

[5] Pingiun YANG. Animation Education Innovative Thinking WayHow to Cultivate the Creative Thinking Way of Students in the Teaching of Network Animation Design [J]. Journal of Information Science and Technology, 2013 (04).

[6] Wenjuan ZHANG, Yongjie TAN. Exploration and discussion on the Flash Animation Design Course Teaching [J]. Journal of Zhoukou Normal College, 2011 (05). 